\title{
More than smart pavements: connected infrastructure paves the way for enhanced winter safety and mobility on highways
}

\author{
Xianming Shi®
}

\begin{abstract}
Currently, there is an urgent demand for more cost-effective, resource-efficient and reliable solutions to address safety and mobility challenges on highways enduring snowy winter weather. To address this pressing issue, this commentary proposes that the physical and digital infrastructures should be upgraded to take advantage of emerging technologies and facilitate the vehicle-infrastructure integration (VII), to better inform decision-makers at various levels. Driven by the paradigm shift towards more automation and more intelligent transportation, it is time to reimagine the vehicle-infrastructure ecosystem with the cold-climate issues in mind, and to enhance communications and coordination among various highway users and stakeholders. This commentary envisages the deployment of vehicleto-everything (V2X) technologies to bring about transformative changes and substantial benefits in terms of enhanced winter safety and mobility on highways. At the center of the commentary is a conceptualized design of next-generation highways in cold climates, including the existing infrastructure entities that are appropriate for possible upgrade to connected infrastructure $(\mathrm{Cl})$ applications, to leverage the immensely expanded data availability fueled by better spatial and temporal coverage. The commentary also advances the idea that $\mathrm{Cl}$ solutions can augment the sensing capabilities and confidence level of connected or autonomous vehicles. The application scenarios of VII system is then briefly explored, followed by some discussion of the paradigm shift towards V2X applications and a look to the future including some identified research needs in the arena of $\mathrm{Cl}$. This work aims to inspire dialogues and synergistic collaborations among various stakeholders of the VII revolution, because the specific challenges call for systematic, holistic, and multidisciplinary approaches accompanied by concerted efforts in the research, development, pilot testing, and deployment of $\mathrm{Cl}$ technologies.
\end{abstract}

Keywords: Connected infrastructure, Intelligent infrastructure, Winter weather, Safety, Mobility, Road maintenance operations, Sensing, Energy harvesting

\section{Introduction}

Winter weather presents a host of profound challenges to the safety, productivity, reliability, and user experience of roadways in cold climates, through reduced visibility and pavement friction, compromised vehicle maneuverability, and decreased traffic speed and volume [1]. In the U.S. alone, traffic crashes on snowy, slushy, or icy pavements have been responsible for more than 1300

Correspondence: xianming.shi@wsu.edu

Department of Civil and Environmental Engineering, Washington State University, P.O. Box 642910, Pullman, WA 99164-2910, USA human fatalities and more than 116,800 human injuries per year [2]. Fu and Kwon [3] reviewed six case studies and found the reductions in traffic volume due to winter weather ranged widely, between $1.8 \%$ for light snowfall and 53\% for heavy snowfall. Kwon et al. [4] collected data for an urban freeway in Canada and their analysis suggested that the free-flow speed and capacity reductions were $17.0 \%$ and $44.2 \%$, respectively, given a snow precipitation rate of $5 \mathrm{~mm} / \mathrm{hr}$. and a Road Surface Index (RSI, a friction-like measure) of 0.2 (snow covered). Climate change can introduce such winter challenges to

\section{Springer Open}

( ) The Author(s). 2020 Open Access This article is licensed under a Creative Commons Attribution 4.0 International License, which permits use, sharing, adaptation, distribution and reproduction in any medium or format, as long as you give appropriate credit to the original author(s) and the source, provide a link to the Creative Commons licence, and indicate if changes were made. The images or other third party material in this article are included in the article's Creative Commons licence, unless indicated otherwise in a credit line to the material. If material is not included in the article's Creative Commons licence and your intended use is not permitted by statutory regulation or exceeds the permitted use, you will need to obtain permission directly from the copyright holder. To view a copy of this licence, visit http://creativecommons.org/licenses/by/4.0/. 
areas unfamiliar with snow and ice conditions, or introduce extreme cold-weather events.

Improving winter road maintenance (WRM) operations and traveler information services could result in fewer crashes, enhanced mobility, fewer emergency service disruptions, reduced travel costs, better fuel economy, and sustained economic productivity. To this end, it is desirable to use the most recent technological advances; current practices [5] include many intelligent transportation system (ITS) solutions such as smart snowplows equipped with automatic vehicle location (AVL), road weather information systems (RWIS), fixed automated spray technology (FAST), maintenance decision support system (MDSS), dynamic message signs (DMSs), and traveler information systems. For traffic management, it is noteworthy that current ITS technologies (loop detectors, video/camera detectors, and radar sensors) are generally limited to obtaining traffic information at the macroscopic level [6]. The advent of technologies in connected and autonomous vehicles (CAVs), Internet of Things (IoT), and advanced driver assistance (ADAS) systems, along with advances in information and communications technology (ICT), is envisaged to bring fundamental changes to the current practices.

The physical and digital infrastructures should be upgraded to take advantage of connected vehicles (CVs)/ autonomous vehicles (AVs) and facilitate the cooperation between roadway infrastructure and CVs/AVs, i.e., vehicle-infrastructure integration (VII). In the near future, one expects to see mixed traffic flows of $\mathrm{CVs}$, $\mathrm{AVs}$, and conventional vehicles on highways. This presents new opportunities for better system performance and higher level of service, along with new infrastructure requirements. For instance, connected infrastructure (CI) solutions are desirable for bridging the communication gap between unconnected vehicles and CVs/AVs. CVs equipped with sensors could enhance mobile road weather data collection [7] and supplement or compliment current roadway sensing entities, raising the effectiveness of the system operations to react to changing conditions. The $360^{\circ}$ awareness by vehicle operators and increased system reliability will help reduce the risk of vehicle crashes and enhance the efficiency of system operations. The Architecture Reference for Cooperative and Intelligent Transportation (ARC-IT) developed by the U.S. Federal Highway Administration (FHWA) has defined how CVs will contribute to various service packages including those for weather, vehicle safety, sustainable travel, traffic management, and traveler information [8]. Earlier work also envisioned that CV technologies would enable traffic managers to deliver real-time, localized road weather advisories and forecasts directly to the vehicle onboard unit as a visual display to drivers [9]. Moreover, collected real-time raw data can be shared with commercial application developers to build valueadded services [10]. AVs tend to be CVs at the same time and can offer a multitude of benefits including alleviated congestion, reduced energy use and emissions, and improved traffic safety $[11,12]$.

Recent years have seen substantial progress in the development and pilot testing of technologies that enable CVs to transmit data to and receive data from other CVs (vehicle-to-vehicle, $\mathrm{V} 2 \mathrm{~V}$ ), to and from infrastructure (vehicleto-infrastructure, V2I), and to and from bicyclists or pedestrians. These can be collectively termed as vehicleto-everything (V2X) communication, for which use cases, requirements, and design considerations of roadways have been discussed by Boban et al. [13].

In the context of upcoming VII revolution and increased road user expectations, this commentary aims to inspire dialogues and synergistic collaborations among various stakeholders and across various disciplines. The commentary is organized in five main sections. Following this introduction is a discussion of conceptual design of next-generation highways in cold climates, including the existing infrastructure entities that are appropriate for possible upgrade to CI applications. Subsequently, the application scenarios of VII system are briefly discussed, with a focus on coordinated truck platooning, safety applications, mobility applications, and road weather applications. The final sections provide concluding remarks regarding the paradigm shift towards V2X applications and a look to the future.

\section{Conceptual design of next-generation highways in cold climates}

Figure 1 presents a conceptual design of next-generation highways in cold climates, where a number of $\mathrm{CI}$ entities are envisioned. These, along with V2X and ICT capabilities, are expected to greatly enhance the spatial and temporal resolutions of road weather data and thus better inform stakeholders such as highway operators, emergency responders, truck drivers and other highway users. They can also augment the sensing capabilities and confidence level of CVs/AVs, reduce the cost and uncertainties of sensing, enrich the sources of information for both CVs/AVs and unconnected vehicles, and improve the response time.

The following sections will further discuss some entities shown in Fig. 1, including:

1. Connected Environmental Sensing Stations (ESS);

2. Connected FAST system;

3. ICT capabilities, including but are not limited to: a) roadside units, b) mobile connectivity, and global positioning system (GPS);

4. Energy-harvesting, connected roadways and roadside infrastructure assets (RIAs); and 


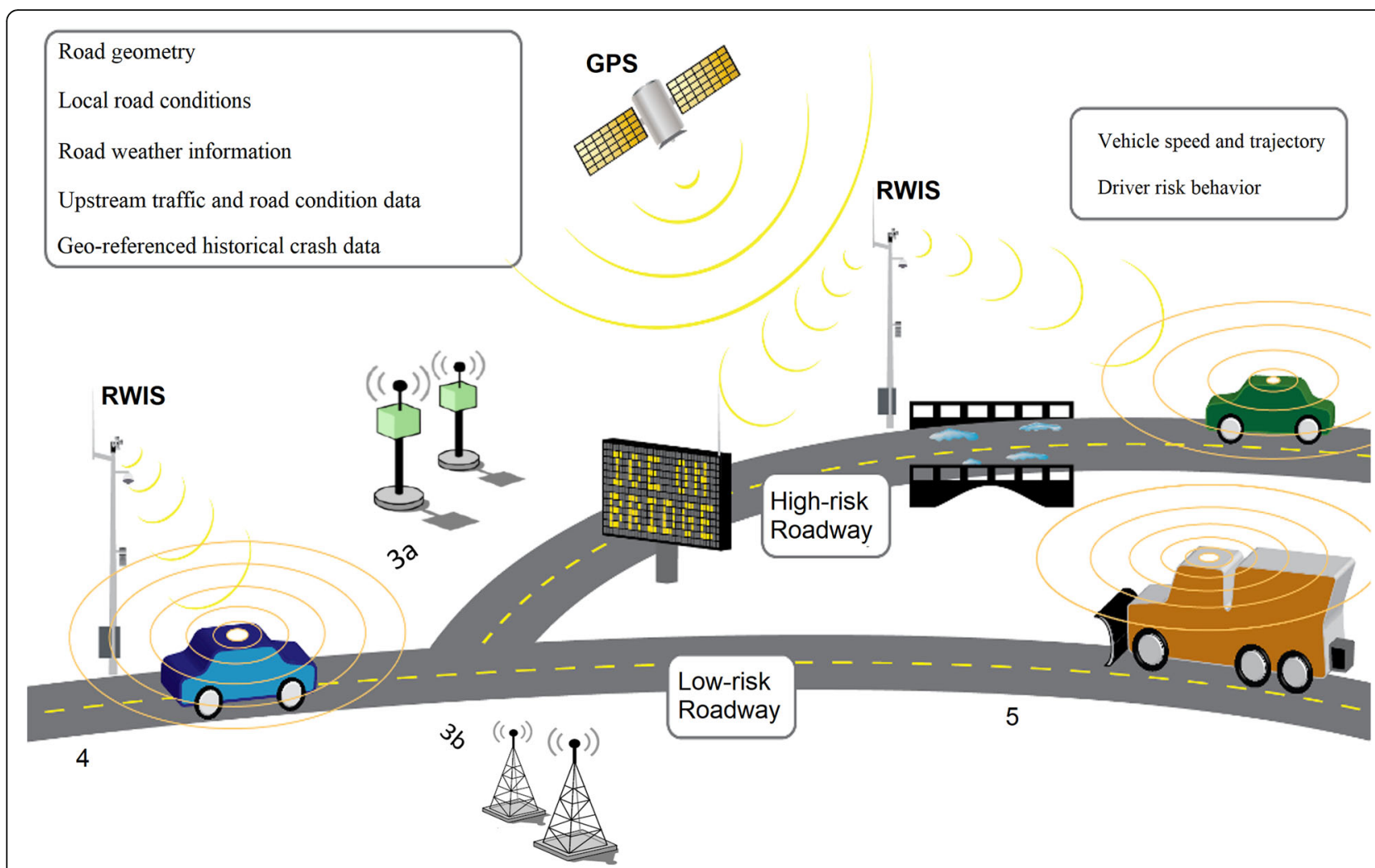

Fig. 1 Conceptual design of next-generation highways in cold climates. Application scenarios include safety applications (e.g., blind spot warning and collision warning) and mobility applications (e.g., traveler information, routing support, and coordinated truck platooning [not shown])

5. Self-sensing and anti-icing pavements.

Note that the 4th and 5th components are secondary to the implementation of VII ecosystem but would greatly enhance the viability and value of VII. Other CI entities will not be discussed in detail, and those may include: weather-responsive traffic signals, smart work zone equipment, and non-contact static charging for vehicles. This work does not cover any discussion of AV-enabling infrastructure components, such as smart signage for automatic driving, standardized pavement markings for machine vision, and magnetic nails and reflective striping for lane-keeping.

\section{Connected ESS}

RWIS-ESS could be further enhanced so as to serve as integral part of the CI solution and of the larger vehicleinfrastructure ecosystem. Currently, this technology is mainly deployed at fixed locations to better inform WRM operators and travelers, and the deployment has been hindered by high cost and maintenance needs. RWIS refers to "networks of ESS that observe the nearsurface atmosphere and pavement surface and subsurface" [14]. Each ESS consists of various sensors that provide site-specific, real-time data on the meteorological conditions, road surface condition (RSC), and subsurface temperature, which altogether enables proactive WRM practices such as anti-icing, improves the roadway level of service and resource allocation, and enhances traveler information, traffic management and emergency response $[15,16]$. Note that the mobile data collection by CVs/AVs will likely bolster the accuracy of road weather forecasting models, which in turn induces advances in the RWIS-ESS technology. This technology is going portable as well [17], and its limitations will likely be overcome by design improvements and cost reductions.

\section{Connected FAST system}

FAST system is a system of fixed assets designed to spray anti-icing liquid on targeted ice-prone or safetycritical areas once the sensors (and associated algorithm) detect the likely risk of ice formation. Many roadway agencies have employed the FAST technology to prevent or proactively mitigate black ice or bonding of compacted snow and ice to pavement (or bridge deck). Conceptually, the design of FAST system could be further enhanced to improve its connectedness and thus contribute to the vehicle-infrastructure ecosystem. Ye et al. [18] surveyed the state of the art of FAST systems and confirmed their potential in delivering substantial 
benefits, such as reduced need for mobile operations and WRM materials and reduced crash frequency and traffic delay. This technology "works best for frost and light snow events", but its application has been hindered by challenges in sensor malfunctioning, system maintenance, and training. A study by Veneziano et al. [19] examined the safety effects of FAST systems operated by the Colorado Department of Transportation and recommended the deployment of such system at "high-traffic, high-crash severity locations". For instance, FAST systems were able to contribute to "an annual reduction of $16 \%$ to $70 \%$ on urban Interstates, $31 \%$ to $57 \%$ on rural Interstates, and $19 \%$ to $40 \%$ on interchange ramps between Interstates", when sited and operated properly.

Arguably, there are a number of roadside or CV solutions other than embedded pavement sensors that can augment the FAST's detection capability and improve its reliability by providing additional information on the RSC. Promising technologies include non-invasive pavement friction sensors [20], vehicle-mounted sensors for thermal mapping [21, 22], slippery surface detection [23], or RSC monitoring [24, 25], and the combined use of mobile camera and smart phone [26] or mobile RWIS technologies [27] for RSC monitoring. Most of them could be readily integrated with the AVL technology [28] to unlock their potential in enabling more proactive, efficient and resilient WRM operations.

\section{ICT capabilities}

This commentary agrees that as part of the transportation cyber-physical system (TCPS), the physical infrastructure of roadways should be "upgraded with digital (ICT) infrastructure that evolves with increasing $\mathrm{CV}$ penetration levels (so as to) create an environment suitable for fostering beneficial V2I innovations" [29]. This is critical for enabling the timely and reliable sensing, processing and communication of the unprecedented amount of data available in the VII environment. Khan et al. [29] summarized the typical roadway digital infrastructure components (as shown in Fig. 2), including roadside units (RSUs), traffic signals, loop detectors, traffic cameras, and DMS communicating with both CVs/AVs and the backend infrastructure (servers) in a real-time or near-realtime fashion.

In the context of VII revolution, no single communication technology "(in the near future) can support such a variety of expected V2X applications for a large number of vehicles", at least not efficiently [30]. Currently, dedicated short-range communications (DSRC) and cellular networks are the two main technologies for V2X communications. Abboud et al. [30] reviewed various DSRC-cellular hybrid architectures and discussed the interworking challenges between the two technologies, with DSRC transceiver embedded in RSUs interacting with in-vehicle onboard units (OBUs) as well as the backhaul network (via cellular or wired Internet connections). Dey et al. [31] developed a method to optimize available communication options for V2V and V2I applications in a heterogeneous wireless network consisting of DSRC and "other wireless technologies (e.g., Wi-Fi, LTE, and WiMAX)". Nonetheless, Jenkins et al. [32] concluded that "DSRC for wireless access in vehicular environments (WAVE) (protocol) is (currently) the only

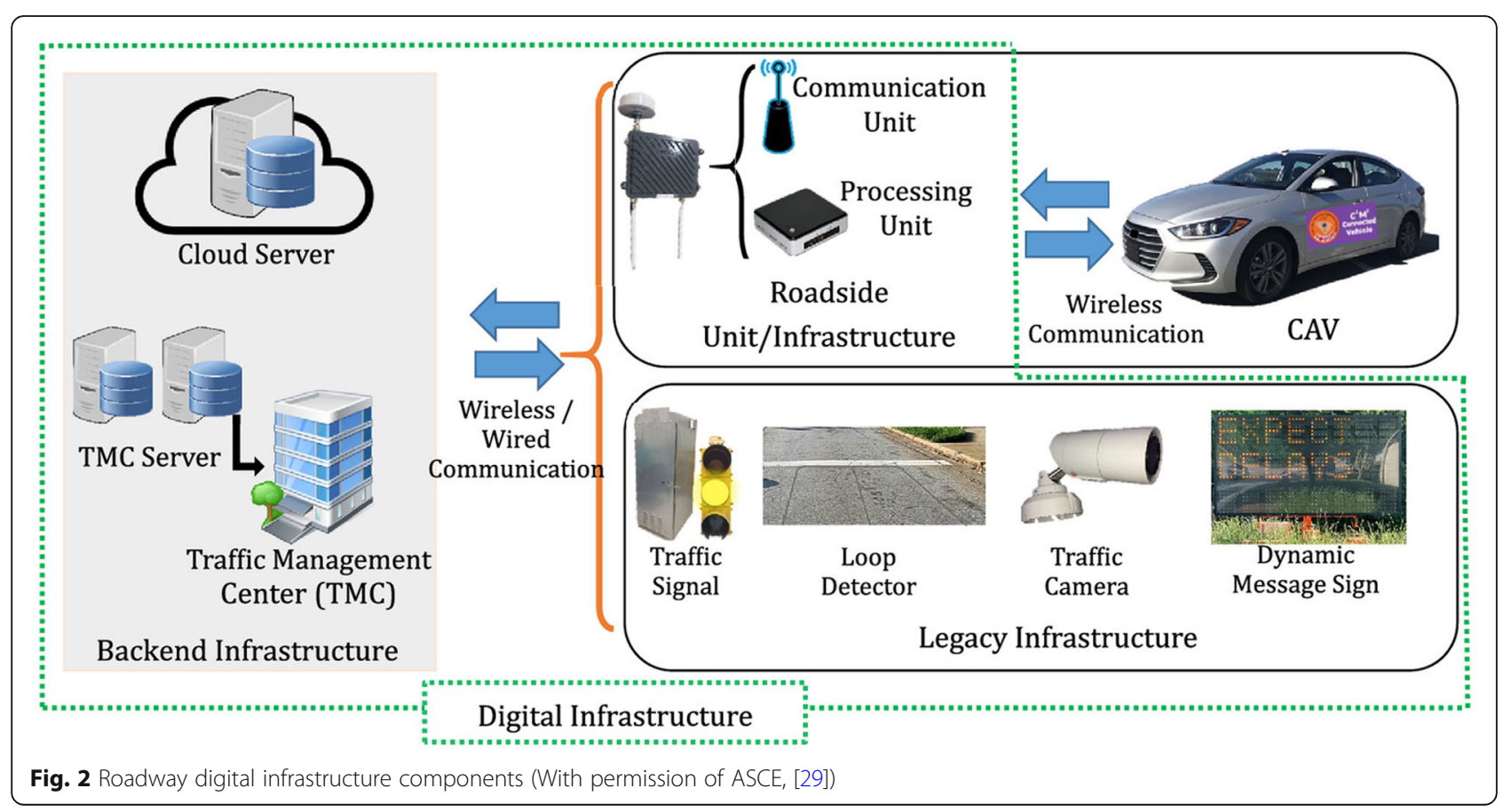


way to provide V2X communications with high reliability and low latency" and thus suitable for dissemination of basic safety messages.

Now is the dawn of the $5 \mathrm{G}$ era, which stands for the 5th generation mobile network and features communication capabilities better meeting the needs of IoT and V2X applications, particularly safety-critical use cases [33]), i.e., higher data rates, ultralow latency, ultrareliability, and increased availability. Boban et al. [33] proposed an architecture of the 5G V2X network, embodied in a heterogeneous multi-radio V2X network designed to leverage the strengths of "cellular systems in centimeter (cmWave) and millimeter (mmWave) frequency bands, vehicular visible light communication (VVLC)" and DSRC/WAVE.

The computing infrastructure, either distributed or centralized, also plays a crucial role in the TCPS to enable smart and seamless mobility, and should be planned, designed, deployed, operated and maintained properly [29]. To attain outstanding performance and reliability of V2X applications, this commentary sees the need for innovations in the field of information technology in terms of system design, hardware and software. Naturally, one needs to tap into recent advances in edge computing, big data analytics, machine learning, artificial intelligence, and so on. For instance, Raza et al. [34] described an advanced ITS based on ultrahigh speed, ultralow latency $5 \mathrm{G}$ scenario, where multiple networking technologies were integrated to provide ubiquitous network connectivity and efficient computing that supports V2X communications. Among them, edge computing (a.k.a., fog computing) refers to "the enabling technologies allowing computation to be performed at the edge of the network, on downstream data on behalf of cloud services and upstream data on behalf of IoT services" [35], and it brings many advantages in "addressing the concerns of response time requirement, battery life constraint, bandwidth cost, and data safety and privacy".

\section{Energy-harvesting, connected roadways and RIAs}

Connected roadways need reliable supply of energy. The massive number of roadway mileages and vast amount of lands in the right-of-way present a great opportunity to capture and utilize the energy dissipated from the ambient roadway system, such as mechanical energy from vehicle or wind loadings and thermal energy from the sun or earth. Such energy harvesting is particularly beneficial for roadways in remote, off-grid areas where the lifeline of CI applications is endangered by the lack of access to power. In the U.S. alone, there are 2.6 million miles of paved roads and highways, of which approximately 93\% has an asphalt surface [36] and 3000 (linear) miles are equipped with noise barrier [37]. The "(unpaved) land cover in close proximity to the National Highway
System" in the U.S. has been estimated to be "roughly 68 percent, or 3.4 million acres" [38].

A suite of on-road energy-harvesting technologies are available, as illustrated in Fig. 3 [39]. These technologies entail the use of piezoelectric materials, micro wind turbines, photovoltaic panels or solar cell roads, geothermal heat pumps or pipe-pavement thermoelectric generator (PP-TEG) system. They could be potentially incorporated into either the connected roadways (such as pavements and traffic signals), or RIAs (such as noise barriers and structural snow fences), to meet the energy needs of a multitude of sensing and communication applications. They also feature a wide variety of cost, energy output and efficiency, service life, dimensions, maintenance requirements, recyclability, and other characteristics. Gholikhani et al. [40] concluded that "thermoelectric and piezoelectric technologies are the most readily available methods" and Wang et al. [39] discussed that technologies other than piezoelectric energy harvesters (PEHs) have their own strengths and limitations. For instance, photovoltaic systems can produce high energy output but the use of solar panels in roadways may complicate vehicle operations or pose a risk to traffic safety, and more research is needed to address such concerns. One promising niche application is solar-powered roadway lighting by light emitting diode (LED) [41]. Geothermal heat pumps are considered a mature technology, which is "geologically and geographically limited" and most appropriate for safety-critical areas, and they have shown a desirable benefit/cost ratio for bridge deck de-icing [42]. While PP-TEG produces a low energy output at high cost and more research is needed to improve the system efficiency [43], a PP-TEG system can be potentially more cost-effective than a piezoelectric system in harvesting renewable energy from pavements $[44,45]$.

The last four years have seen increased interest and promising progress in demonstrating the use of piezoelectric materials to harvest deformation energy from asphalt pavement. Yet, the amount of energy harvested is limited and mainly suitable for applications such as "powering wireless sensors embedded into pavement structure" [46] and other microelectronics, "heating road surface on bridge deck for anti-icing, lighting, or powering traffic devices" [39]. A few representative advances in the development of piezoelectric energy harvester (PEH) technology is summarized in Table 1.

In addition to smart pavements, there are a number of conceptual scenarios that energy-harvesting technologies may be incorporated into the roadway infrastructure. For instance, portable micro wind turbines could be mounted on structural snow fences, traffic signals, and so on. Being a cost-effective technology to prevent blowing and drifting snow, snow fences can improve road safety and provide additional benefits, if designed and 


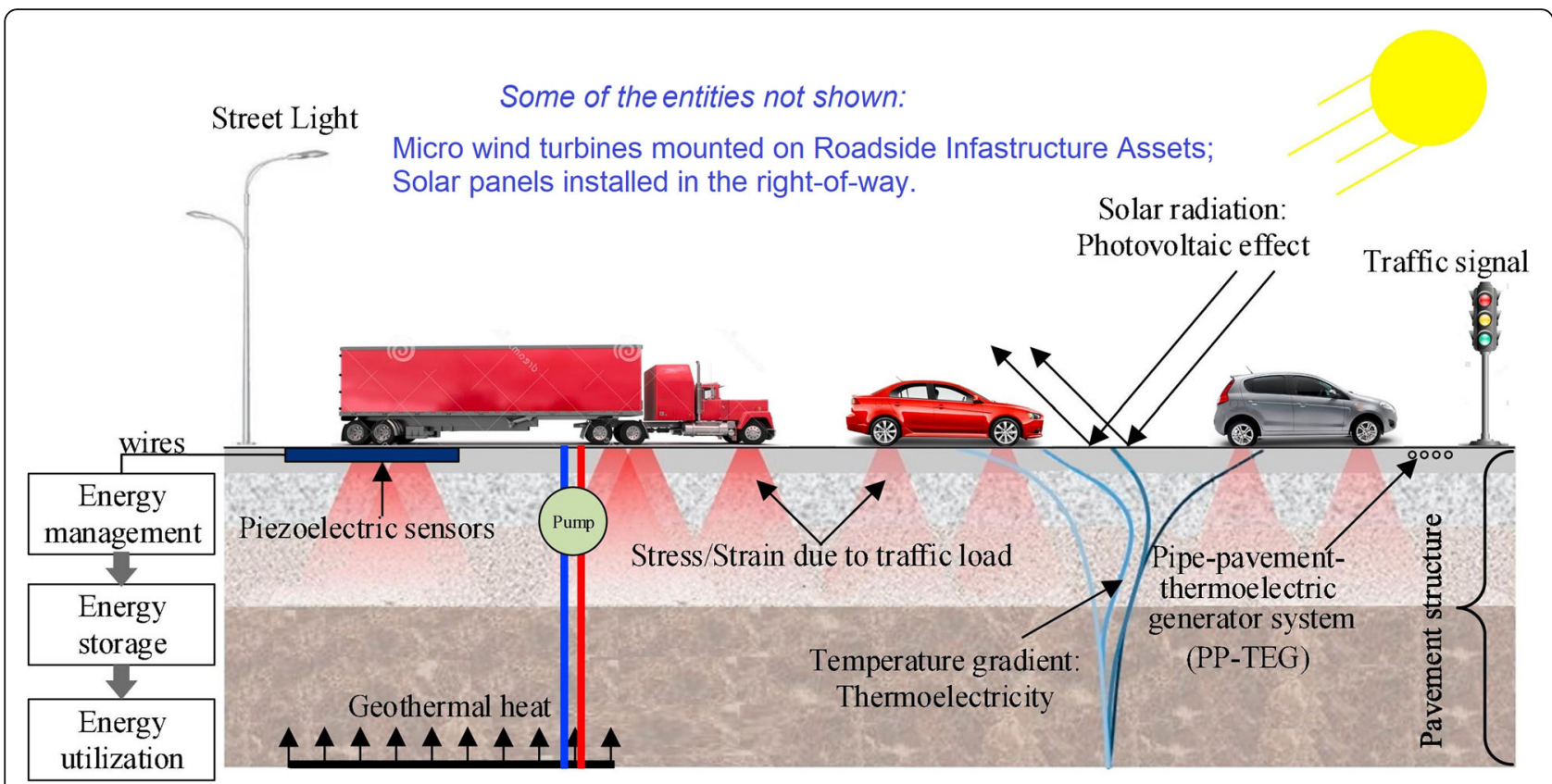

Fig. 3 Available on-road energy-harvesting technologies (modified from [39], courtsey of Elsevier)

Table 1 Recent advances in PEH technology for roadways

Configuration
A stacked configuration of
transducers
Stacked units including U-
shaped interlayer copper foi

shaped interlayer copper foil electrode structure

Bridge transducer with layered poling and electrode design

Several PEH prototypes to be embedded into asphalt pavement

One layer of "piezoelectric elements with a higher piezoelectric stress constant" and two layers of "more flexible conductive asphalt mixtures"

A 100-m piezoelectric pavement with packaged multilayer transducer

\section{Optimal energy performance}

Not reported

Output power: $22.8 \mathrm{~mW}$ at a resistive load of $20 \mathrm{k} \Omega$, under $0.7 \mathrm{MPa}$ (compression loading) and $10 \mathrm{~Hz}$ (vibration frequency); output voltage: $28.0 \mathrm{~V}$

Output power: $2.1 \mathrm{~mW}$ at a resistive load of $400 \mathrm{k} \Omega$, under $0.07 \mathrm{MPa}, 5 \mathrm{~Hz}$; output voltage: $556 \mathrm{~V}$

Output power: > $25 \mathrm{~mW}$ under $15 \mathrm{MPa}$ (for each piezoelectric element) and 10 $\mathrm{Hz}$; output voltage (nearly 20 V) and output current ( $>$ $100 \mu \mathrm{A}$ ) at a load of $3 \mathrm{kN}$

Output power: ranging from $1.2 \mathrm{~mW}$ to $300 \mathrm{~mW}$ at $30 \mathrm{~Hz}$

Output power: up to $231 \mathrm{~mW}$ $(0.58 \mathrm{~J})$, under $0.7 \mathrm{MPa}$

\section{Other performance considerations}

Able to support loadings up to $150 \mathrm{kN}$ and remained effective after 100,000 cyclic loadings

Stable performance after 50 , 000 simulated cyclic loading, with attenuations of: opencircuit voltage by $4.4 \mathrm{~V}$, output power by $3.3 \mathrm{~mW}$

Balanced the desire for improved energy output and the need for less risk of stress concentration

Higher frequency "represents higher traffic speed and greater traffic volume" (e.g., on Interstate highways), and leads to better output power.

The cost of electricity produced by this $\mathrm{PEH}$ can be as low as "\$19.15/kWh at a high-volume roadway within a 15-year service life".

Under the daily traffic volume of 15,100 vehicles, this $100-m$ pavement can produce up to $1.93 \mathrm{MJ}$ (i.e., the energy needs of 35 mobile phones). The additional construction cost: approximately $\$ 57 / \mathrm{m}$. Jasim et al. [49]

\section{Reference}

Yang et al. [47]

Wang et al. [48]

\section{Jasimet al. [49]}

Roshani et al. [46]

Guo and Lu [44, 45]

Cao et al. [50] 
sited properly [51]. Nabavi and Zhang [52] reported three groups of portable wind energy harvesters, i.e., piezoelectric-, electromagnetic-, and electrostatic-based generators, with different wind-flow-trapping mechanisms and varying dimensions and energy conversion efficiencies. Photovoltaic panels can be strategically installed either in the right-of-way providing sufficient space for such a "distributed solar power plant" [53], or integrated with noise barriers to produce a considerable amount of renewable energy [37]. Qiao et al. [54] proposed the concept of a "smart microgrid that optimally utilizes the public right-of-way and roadway infrastructure to provide cost-effective, highly efficient, and reliable electric power production, distribution, storage, and utilization". The design entails a "grid-connected wind/ solar hybrid generation system installed on the pole of a roadway/traffic signal light". Considering the great temperature difference between the air and the relatively warm soil beneath pavement, another potential technology to explore is thermoelectric generators. With the thermal gradient in the opposite direction, this concept was demonstrated in south Texas [55] where a TEG prototype produced "an average of $10 \mathrm{~mW}$ of electric power continuously over a period of $8 \mathrm{~h}$ ".

\section{Self-sensing and anti-icing pavements}

Self-sensing pavements can serve as an integral part of connected roadway infrastructure or VII system, and the related research is still in the burgeoning stage and the cost-effectiveness of this technology over the long term remains unknown. Han et al. [56] reported the traffic detection performance of a self-sensing pavement being tested at the Minnesota Road Research Facility, USA, both in winter and in summer. This smart pavement was enabled by the admixed carbon nanotubes in concrete, and was able to "accurately detect the passing of different vehicles under different vehicular speeds and test environments". Relative to conventional strain gauges, this self-sensing concrete exhibited advantages in its ease of installation and maintenance, compatibility with pavement structures, and durability. Liu et al. [57] reported an exploratory study that suggests the potential use of conductive asphalt materials for self-sensing applications, because the different stages of damage evolution correspond to certain change patterns in their electrical resistivity. Xiang et al. [58] reported the use of piezoelectric sensors to detect moving traffic loads on pavement, i.e., for weigh-in-motion application.

Anti-icing pavements are often not designed for CI applications, but they can contribute to the mobility of surface transportation system during snowy weather. A variety of technologies have been explored to enable antiicing pavements, ranging from "anti-freezing pavements that rely on physical action, to high-friction in situ anti- icing polymer overlays, to asphalt pavements containing anti-icing additives, to heated pavements using energy transfer systems" [59]. All of them aim to "prevent or reduce the bond of ice or compacted snow to pavement or to prevent or treat winter precipitation". Pan et al. [60] and Zhang et al. [61] presented a comprehensive review on the use of conductive and salt-releasing asphalt mixtures as anti-icing pavements, respectively. Saleh et al. [62] discussed the design, construction and evaluation of hydronic asphalt pavement (HAP), which is another energyharvesting technology explored for anti-icing (and deicing) applications. Johnsson [63] found that HAP could be engineered as part of a system to harvest sufficient geothermal energy for areas with mild winters and greatly "reduce the annual number of hours with risk for ice formation". Note that none of these technologies have been widely adopted by transportation agencies, and this is mainly due to concerns over their long-term performance and cost. Nonetheless, this Commentary proposes that there is great potential in overcoming the technological barrier in the near future.

\section{Application scenarios of VII system}

This section identifies some possible application scenarios of VII system, which are grouped into safety, mobility, road weather, agency data, and other categories, as detailed in Table 2. One can expect CI-enabled improvements to be materialized in these applications, given the notable advances in spatial and temporal coverage offered by CI technologies. The key to success is the timely and reliable sensing, processing and communication of the big data collected by the VII system. Table 2 is not intended to be comprehensive, as innovations may lead to new possibilities and new application scenarios.

It is noteworthy that the enhanced spatial and temporal resolutions of road weather data can better inform a multitude of stakeholders and produce benefits across the spectrum of many applications. Both road weather and agency data applications are intertwined with highway safety and mobility objectives, because they aim to "provide a safe and efficient transportation system to move people and goods" [12]. The USDOT V2I research program has developed a computing platform known as V2I hub [87], which "interfaces with a variety of ITS equipment such as RSU, traffic signal controllers, and DMS" and the GPS and transportation management center (TMC). For instance, an RSU can broadcast intersection geometry data (a.k.a., MAP message), signal phase and timing (SPaT) message, GPS correction data, and curve speed warning to incoming vehicles, or receive them from nearby RSUs $([87,88])$.

The USDOT has estimated that combined V2V and V2I systems may potentially address about $81 \%$ of allvehicle target crashes, $83 \%$ of all light-vehicle target 
Table 2 Some identified application scenarios of VII system

\begin{tabular}{|c|c|c|}
\hline Application Type & Application Scenario & Reference \\
\hline \multirow[t]{9}{*}{ Safety } & $\begin{array}{l}\text { Cooperative-ITS platform: advance warning of hazardous road } \\
\text { situations (to vehicle drivers) }\end{array}$ & Padarthy and Heyns [23] \\
\hline & V2X applications for roadway safety and vehicle safety & Abboud et al. [30]; FHWA [64] \\
\hline & $\begin{array}{l}\text { Intersection collision warning, emergency vehicle pre-emption, work } \\
\text { zone alerts, curve speed warning, railroad crossing violation warning }\end{array}$ & Barbaresso and Johnson [65] \\
\hline & $\begin{array}{l}\text { In-vehicle signage, oversize vehicle warning, red-light or stop-sign vio- } \\
\text { lation warning, reduced speed zone warning/lane closure, restricted } \\
\text { lane warning, spot weather impact warning }\end{array}$ & Iteris [66] \\
\hline & Cooperative collision avoidance & $\begin{array}{l}\text { Chowdhury et al. [67]; Wang and Li } \\
\text { [68] }\end{array}$ \\
\hline & Blind spot warning and lane change warning & Theriot et al. [69]; Howe et al. [70] \\
\hline & ADAS functionalities & Liu et al. [71] \\
\hline & Pedestrian detection and warning & He and Zeng [72] \\
\hline & $\begin{array}{l}\text { Deer crossing road detection: with multiple roadside LiDAR (Light } \\
\text { Detection and Ranging) sensors deployed to enable real-time, micro- } \\
\text { level and high-resolution sensing of road users }\end{array}$ & $\mathrm{Wu}[6]$ \\
\hline \multirow[t]{10}{*}{ Mobility } & Coordinated truck platooning & $\begin{array}{l}\text { Gungor and Al-Qadi [73]; Gungor } \\
\text { and Al-Qadi [73] }\end{array}$ \\
\hline & Traffic management and sustainable travel & $\begin{array}{l}\text { Li et al. [76]; Gopalakrishna, et al. [77]; } \\
\text { Iteris [8] }\end{array}$ \\
\hline & $\begin{array}{l}\text { Advanced traveler information system, corridor management, transit } \\
\text { vehicle priority, and multimodal intelligent traffic signal system }\end{array}$ & Barbaresso and Johnson [65] \\
\hline & V2X applications for vehicle traffic optimization & Abboud et al. [30] \\
\hline & $\begin{array}{l}\text { Incident detection and response; traffic queue or bottleneck detection; } \\
\text { traffic network flow optimization }\end{array}$ & $\begin{array}{l}\text { Khazraeian [78]; Chowdhury et al. } \\
\text { [67] }\end{array}$ \\
\hline & Emergency vehicle priority & Head [79] \\
\hline & Adaptive signal control & Yao et al. [80] \\
\hline & Cooperative adaptive cruise control & Huang et al. [81] \\
\hline & Dynamic routing support & Genders and Razavi [82] \\
\hline & $\begin{array}{l}\text { Smart DMS, routing support and data-driven apps for freight carriers, } \\
\text { transit vehicles and emergency responders }\end{array}$ & Iteris [66]; Akin et al. [83] \\
\hline Road weather & $\begin{array}{l}\text { V2X applications for motorist advisories and warnings, information for } \\
\text { maintenance and fleet management systems, and MDSS }\end{array}$ & $\begin{array}{l}\text { Barbaresso and Johnson [65]; Young } \\
\text { et al. [84]; FHWA [64] }\end{array}$ \\
\hline Agency Data & $\begin{array}{l}\text { V21 applications for probe-based traffic monitoring, probe-based pave- } \\
\text { ment condition monitoring, and performance measures }\end{array}$ & $\begin{array}{l}\text { Barbaresso and Johnson [65]; FHWA } \\
\text { [9]; Li et al. [85, 86] }\end{array}$ \\
\hline \multirow[t]{2}{*}{ Other } & $\begin{array}{l}\text { V2X applications for passenger infotainment (via in-vehicle Internet ac- } \\
\text { cess) and car manufacturer services (e.g., point-of-interest notification } \\
\text { and remote vehicle diagnostics). }\end{array}$ & Abboud et al. [30] \\
\hline & Value-added services by commercial application developers & Chapman and Drobot [10] \\
\hline
\end{tabular}

crashes, and $72 \%$ of all heavy-truck target crashes [89]. Such safety benefits of CV technologies are likely to be more significant during adverse weather conditions, by enhancing all levels of decision-making by stakeholders. For example, the enriched road weather condition information can be communicated to the general public in a timely fashion, such that they can stay home, choose a different route, or slow down in light of inclement weather.

In addition to safety benefits, the deployment of V2X technologies and advances in VII are likely to produce mobility and resilience benefits on winter highways, by better informing all the stakeholders and enabling location-specific and timelier detection of and response to disruptions. By definition, resilience is "the ability of a system to resume normal function at a performance level (comparable to) which existed before a disruptive event", and can be characterized by metrics such as robustness, adaptability, agility, redundancy, response time, recovery time, level of recovery, and performance loss [90]. The transmission of microlevel road weather data by vehicles through V2X communication has been demonstrated in the European WiSafeCar project [91], which is anticipated to benefit the efficiency of road weather management [92]. 
One major mobility application scenario is coordinated truck platooning. Connected and autonomous trucks (CATs) are increasingly introduced into the market, which enables the grouping of densely-spaced trucks to travel together on highways to save on the cost and fuel consumption and improve the efficiency of freight operations. This practice, known as truck platooning, has unintended negative consequences such as exacerbated damage in pavement structure, induced by the "channelized truck loading application" [73]. To mitigate this detrimental effect, Gungor and Al-Qadi [73] proposed a framework to optimally randomize the pattern of axel loadings of truck platoons using V2I communication. Such a coordinated truck platooning approach entails cooperative automation among trucks and roadway infrastructure, which uniformly distributes the loadings of truck platoons over the pavement lanes, leading to an overall reduction in damage accumulation in the pavement and a longer service life of the pavement.

It is interesting to note that winter weather may induce vulnerabilities in vehicles on highways as well as in physical and digital infrastructures. For instance, the performance and reliability of CVs/AVs (and other sensors) and communications could be destabilized by extremely cold temperatures and heavy snowfall conditions, and such risks should be considered in the design of the VII system to operate in cold climates.

\section{Conclusion and outlook}

Currently, there is an urgent demand for more costeffective, resource-efficient and reliable solutions to address safety, mobility, and resilience challenges on highways enduring snowy winter weather. One can envisage a fundamentally changed landscape for WRM operations, traveler information, and traffic management on winter highways, amid the increasing introduction of innovative concepts (e.g., Smart Cities, Crowdsourcing, and $\mathrm{V} 2 \mathrm{X}$ ) and more penetration of emerging technologies (e.g., CVs/AVs/CATs, IoT, 5G, Cloud Computing, Edge Computing, and Artificial Intelligence) into the transportation sector. These concepts and technologies will catalyze the increasing momentum of VII to enable a significantly higher level of service. As such, there is the need to conceptualize and strategically plan for a more connected roadway infrastructure for VII system, even though many of the CI solutions are still in the nascent stages of development.

Driven by the paradigm shift towards more automation and more intelligent transportation, it is time to reimagine the vehicle-infrastructure ecosystem with the cold-climate issues in mind, and to enhance communications and coordination among various highway users and stakeholders. A next step is to promote the synergies among the enabling technologies and unlock their potential for the specific needs of highway agencies. For instance, CI technologies are currently less mature than $\mathrm{CV}$ technologies. Great benefits can be achieved by integrating the array of both $\mathrm{CI}$ and $\mathrm{CV}$ technologies. Because such integration would provide better, more accurate and timely knowledge of conditions throughout the roadway network (albeit with a focus on critical locations and segments), in terms of traffic characteristics, RSCs, and environmental conditions. This big data could be processed, archived, and communicated to highway operators and traveling public in a timely fashion. In addition to informing travelers, such information can be fed into agency decision support tools such as the Maintenance Decision Support System (Ye et al. [74], Rennie and Groeneweg [75]) to greatly benefit the roadway level of service and the overall safety, mobility, and productivity of the surface transportation system.

To inspire dialogues and synergistic collaborations among various stakeholders of the VII revolution, this commentary has underscored the need to plan, design, and engineer a multifunctional, next-generation highway infrastructure that is more intelligent, safer and more resilient and adaptive than the conventional highway infrastructure, fueled by more reliable and rapid collection, processing and communication of big data.

The challenges in achieving better safety and mobility on winter highways may continue to evolve and they must be addressed with systematic, holistic, and multidisciplinary approaches. A next step is to carry out concerted efforts in the research, development, pilot testing, and deployment of CI technologies, which needs to bring together expertise from different disciplines to transform the built highway environment to one that better facilitates the real-time detection of localized conditions and the flow of high-quality road weather data (e.g., V2X). The ultimate goal is to improve the safety and mobility of highways in cold climates, which in turn would translate to a broad array of social, economic and environmental benefits.

The VII revolution is still in its infancy and there are many unexplored territories and dynamics, unanswered questions, and open challenges. Innovations are much needed to overcome the various technological and institutional barriers and to achieve the successful implementation of VII system for highways in cold climates, and to maximize the synergies between the physical and digital infrastructures. It is imperative to note, however, that innovations should be anchored in answering the user requirements, i.e., following a needs-pull (vs. technologypush) approach.

\section{Recommendations}

The following presents some research needs identified in the arena of $\mathrm{CI}$ : 
- Tap into recent advances in various V2X and ICT technologies and investigate better compatibility, automation, and integration among them, to provide the best possible road weather information, in terms of spatial and temporal resolutions, reliability, and so on. The efforts may be in the aspects of system design [85, 86, 90], hardware, and software and should take into account the given constraints of cost, communications speed and reliability, as well as the specific performance requirements and functionalities needed by the VII system. The objective is to have a cohesive, user-friendly and affordable VII system that operates efficiently and reliably during disruptive weather of snow and ice.

- Address the technical and non-technical challenges vis-à-vis scalability, interoperability, privacy and security, in anticipation of increased number and heterogeneity of smart devices and immense amount of sensor data available, similar to those hindering the implementation of Smart City services and applications [93].

- Investigate the transformation of physical roadway infrastructure for the needs of VII applications, build resilience into highways, and tap into the opportunities of improving the design, health monitoring and diagnosis, preservation, and utility of roads, bridges, tunnels, culverts, and RIAs, while reducing their life-cycle cost and environmental footprints.

- Develop and demonstrate technologies that can reliably supply cost-effective energy for roadways in remote, off-grid areas. A promising approach could be the hybrid use of PEHs and pyroelectric materials. Future research should focus on achieving balanced performances in energy output and costefficiency, reliability and resilience, durability, recyclability, and sustainability over the life cycle of the energy harvesting system. Areas of improvement may include: the selection and design of materials, PEH design (packaging, composite configuration of elements, etc.) and power electronics, optimized as a function of given traffic patterns, in-service environmental conditions, and specific energy requirements of the CI application.

- Develop and demonstrate a set of cost-effective, durable asphalt pavement mixtures or surface layers that enable reliable real-time detection of key vehicle flow parameters and other functionalities such as in situ anti-icing, sensing of the surface condition (dry, wet, snowy, icy, etc.) and/or sensing of the overall health condition of the pavement itself.

\section{Abbreviations}

ADAS: Advanced driver assistance; ARC-IT: Architecture Reference for Cooperative and Intelligent Transportation; AVL: Automatic vehicle location;
CATs: Connected and autonomous trucks; CAVs: Connected and autonomous vehicles; Cl: Connected infrastructure; CV: Connected vehicle; DMS: Dynamic message sign; DSRC: Dedicated short-range communications; ESS: Environmental sensing station; FAST: Fixed automated spray technology; FHWA: Federal Highway Administration; GPS: Global positioning system; HAP: Hydronic asphalt pavement; ICT: Information and communications technology; IOT: Internet of Things; ITS: Intelligent transportation system; PEH: Piezoelectric energy harvester; LiDAR: Light Detection and Ranging; LTE: Long-Term Evolution; OBU: Onboard unit; PP-TEG: Pipe-pavement thermoelectric generator; RIA: Roadside infrastructure asset; RSC: Road surface condition; RSU: Roadside unit; RWIS: Road weather information system; TCPS: Transportation cyber-physical system; TMC: Transportation management center; V2I: Vehicle-to-infrastructure; V2X: Vehicle-to-anything; V2V: Vehicle-to-vehicle; VII: Vehicle-infrastructure integration; WLC: Vehicular visible light communication; USDOT: U.S. Department of Transportation; WAVE: Wireless access in vehicular environments; WiMAX: Worldwide Interoperability for Microwave Access; WRM: Winter road maintenance

\section{Acknowledgments}

The author acknowledges the editorial assistance from Ms. Cheryl Reed and the constructive criticism by the anonymous reviewers.

Author's contributions

XS contributed solely to this commentary. The author(s) read and approved the final manuscript.

\section{Funding}

The author would like to acknowledge funding support from the Center for Advanced Multimodal Mobility Solutions and Education (CAMMSE), a Tier 1 UTC (University Transportation Center) sponsored by the US Department of Transportation.

\section{Availability of data and materials}

All data have been presented in the Commentary.

Ethics approval and consent to participate

Not applicable.

Consent for publication

Not applicable.

\section{Competing interests}

The author declares that he has no competing interests.

Received: 27 May 2020 Accepted: 7 November 2020

Published online: 19 November 2020

\section{References}

1. Strong CK, Ye Z, Shi X (2010) Safety effects of winter weather: the state of knowledge and remaining challenges. Transp Rev 30(6):677-699

2. FHWA (2011) Snow and ice. Road weather management, Federal Highway Administration, U.S. Department of Transportation, Washington, D.C Accessed 10 Aug 2011. [online]. http://ops.fhwa.dot.gov/Weather/weather_ events/snow_ice.htm

3. Fu L, Kwon TJ (2018) Chapter 8: mobility effects of winter weather and road maintenance operations. In: Shi X, Fu L (eds) Sustainable Winter Road Operations. Wiley-Blackwell, USA pp 131-155

4. Kwon TJ, Fu L, Jiang C (2013) Effect of winter weather and road surface conditions on macroscopic traffic parameters. Transp Res Rec 2329:54-62

5. Shi X, Fu L (2018) Sustainable winter road operations. Wiley Blackwell, USA

6. Wu J (2018) Data processing algorithms and applications of LiDARenhanced connected infrastructure sensing (doctoral dissertation)

7. Dey KC, Mishra A, Chowdhury M (2015) Potential of intelligent transportation systems in mitigating adverse weather impacts on road mobility: a review. IEEE Trans Intell Transp Syst 16(3):1107-1119

8. Iteris (2020). "ARC-IT version 8.3, Service Packages." [Online]. Available: https://local.iteris.com/arc-it/html/servicepackages/servicepackagesareaspsort.html. Accessed on 18 Sept 2020.

9. FHWA (2014). "Connected Vehicle Reference Implementation Architecture 2014." [Online]. Available: http://www.iteris.com/cvria/. Accessed on 12 Nov 2014 
10. Chapman MB, Drobot S (2012) The use of connected vehicle observations in weather applications for various highly impacted users of the roads. In: Proc. 16th Int. Road Weather Conf., Helsinki, Finland, pp 1-7

11. Shladover S (2013) Why automated vehicles need to be connected vehicles. In: IEEE Vehicular Networking Conference [online]. http://www.ieeevnc.org/2 013/media/IEEE_VNC_BostonKeynote_Shladover.pdf. Accessed 1 Oct 2013

12. Sobanjo JO (2019) Civil infrastructure management models for the connected and automated vehicles technology. Infrastructures 4(3):49

13. Boban M, Kousaridas A, Manolakis K, Eichinger J, Xu W (2018) Connected roads of the future: use cases, requirements, and design considerations for vehicle-to-everything communications. IEEE Veh Technol Mag 13(3):110-123

14. Albrecht C, Patterson R, Sturges $L$ (2018) Weather Services for Sustainable Winter Road Operations. Sustainable Winter Road Oper 2318:58

15. Strong C, Fay L (2007) RWIS usage report. Alaska DOT and Public Facilities, Final Report. Division of Program Development, Juneau

16. Kwon TJ, Fu L, Melles SJ (2017) Location optimization of road weather information system (RWIS) network considering the needs of winter road maintenance and the traveling public. Computer-Aided Civil Infrastructure Eng 32(1):57-71

17. Tessier R (2016) Evaluation of Portable Road Weather Information Systems (no. UMTC-16.03). Dept. of Transportation. Office of Transportation Planning, Massachusetts

18. Ye Z, Wu J, Ferradi NE, Shi X (2013) Anti-icing for key highway locations: fixed automated spray technology. Can J Civ Eng 40(1):11-18

19. Veneziano D, Muthumani A, Shi X (2015) Safety effects of fixed automated spray technology systems. Transp Res Rec 2482(1):102-109

20. Ewan L, Al-Kaisy A, Veneziano D (2013, January) Remote sensing of weather and road surface conditions: Is technology mature for reliable ITS applications. In: TRB 2013 Annnual Meeting, pp I-18

21. Todeschini I, Di Napoli C, Pretto I, Merler G, Cavaliere R, Apolloni R et al (2016, August) Thermal mapping as a valuable tool for road weather forecast and winter road maintenance: an example from the Italian Alps. In: Fourth International Conference on Remote Sensing and Geoinformation of the Environment (RSCy2016), vol 9688. International Society for Optics and Photonics, Paphos, p $96880 \mathrm{H}$

22. Hu Y, Almkvist E, Gustavsson T, Bogren J (2019) Modeling road surface temperature from air temperature and geographical parameters -implication for the application of floating Car data in a road weather forecast model. J Appl Meteorol Climatol 58(5):1023-1038

23. Padarthy M, Heyns E (2019) Identification and classification of slippery winter road conditions using commonly available vehicle variables. Transp Res Rec 2673(2):60-70

24. Chen K, Lu M, Fan X, Wei M, Wu J (2011, August) Road condition monitoring using on-board three-axis accelerometer and GPS sensor. In: 2011 6th International ICST conference on communications and networking in China (CHINACOM). IEEE, Harbin, pp 1032-1037

25. Pu Z, Liu C, Wang Y, Shi X, Zhang C (2019) Road Surface Condition Prediction using Long Short-Term Memory Neural Network based on Historical Data (no. 19-03118)

26. Linton MA, Fu L (2016) Connected vehicle solution for winter road surface condition monitoring. Transp Res Rec 2551(1):62-72

27. Ye Z, Shi X, Strong CK, Larson RE (2012) Vehicle-based sensor technologies for winter highway operations. IET Intell Transp Syst 6(3):336-345

28. Santiago-Chaparro KR, Chitturi M, Szymkowski T, Noyce DA (2012) Evaluation of performance of automatic vehicle location and TowPlow for winter maintenance operations in Wisconsin. Transp Res Rec 2272(1):136143

29. Khan SM, Chowdhury M, Morris EA, Deka L (2019) Synergizing roadway infrastructure investment with digital infrastructure for infrastructure-based connected vehicle applications: review of current status and future directions. J Infrastruct Syst 25(4):03119001

30. Abboud K, Omar HA, Zhuang W (2016) Interworking of DSRC and cellular network technologies for V2X communications: a survey. IEEE Trans Veh Technol 65(12):9457-9470

31. Dey KC, Rayamajhi A, Chowdhury M, Bhavsar P, Martin J (2016) Vehicle-tovehicle (V2V) and vehicle-to-infrastructure (V2I) communication in a heterogeneous wireless network-performance evaluation. Transport Res Part C: Emerg Technol 68:168-184

32. Jenkins M, Duggan D, Negri A (2017, March) Towards a connected bicycle to communicate with vehicles and infrastructure: multimodel alerting interface with networked short-range transmissions (MAIN-ST). In: 2017 IEEE
Conference on Cognitive and Computational Aspects of Situation Management (CogSIMA). IEEE, Savannah, pp 1-3

33. Boban M, Manolakis K, Ibrahim M, Bazzi S, Xu W (2016, October) Design aspects for 5G V2X physical layer. In: 2016 IEEE Conference on Standards for Communications and Networking (CSCN). IEEE, Berlin, pp 1-7

34. Raza N, Jabbar S, Han J, Han K (2018, June) Social vehicle-to-everything (V2X) communication model for intelligent transportation systems based on 5G scenario. In: Proceedings of the 2nd International Conference on Future Networks and Distributed Systems, pp 1-8

35. Shi W, Cao J, Zhang Q, Li Y, Xu L (2016) Edge computing: vision and challenges. IEEE Internet Things J 3(5):637-646

36. Mohamed Jaafar ZFB (2019) Computational modeling and simulations of condition deterioration to enhance asphalt highway pavement design and asset management. In: Dissertation for Ph.D. in engineering science. University of Mississippi, electronic theses and dissertations, vol 1643 https://egrove.olemiss.edu/etd/1643

37. Poe C, Plovnick A, Hodges T, Hastings A, Dresley S (2017) Highway renewable energy: photovoltaic noise barriers (no. DOT-VNTSC-FHWA-17-20; FHWA-HEP-17-088). Federal Highway Administration. Office of Natural Environment, United States

38. Earsom, S., Hallett, R., Perrone, T., Poe, C., \& Greenfield, M. (2010). Carbon sequestration pilot program results: estimated land available for carbon sequestration in the National Highway System. Report for the Federal Highway Administration, Washington, D.C.

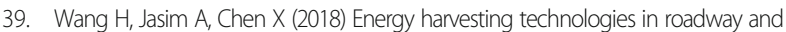
bridge for different applications-a comprehensive review. Appl Energy 212:10831094

40. Gholikhani M, Roshani H, Dessouky S, Papagiannakis AT (2020) A critical review of roadway energy harvesting technologies. Appl Energy 261:114388

41. Yoomak S, Jettanasen C, Ngaopitakkul A, Bunjongjit S, Leelajindakrairerk M (2018) Comparative study of lighting quality and power quality for LED and HPS luminaires in a roadway lighting system. Energy Buildings 159:542-557

42. Habibzadeh-Bigdarvish O, Yu X, Lei G, Li T, Puppala AJ (2019) Life-cycle costbenefit analysis of bridge deck de-icing using geothermal heat pump system: a case study of North Texas. Sustain Cities Soc 47:101492

43. Zhu $X, Y U$ Y, Li F (2019) A review on thermoelectric energy harvesting from asphalt pavement: configuration, performance and future. Constr Build Mater 228:116818

44. Guo L, Lu Q (2017a) Potentials of piezoelectric and thermoelectric technologies for harvesting energy from pavements. Renew Sust Energ Rev 72:761-773

45. Guo L, Lu Q (2017b) Modeling a new energy harvesting pavement system with experimental verification. Appl Energy 208:1071-1082

46. Roshani H, Dessouky S, Papagiannakis AT, Montoya A (2017) Experimental and finite element assessment of three energy harvesting prototypes for roadways. Innov Infrastructure Sol 2(1):7

47. Yang H, Wang L, Hou Y, Guo M, Ye Z, Tong X, Wang D (2017) Development in stacked-array-type piezoelectric energy harvester in asphalt pavement. Mater Civ Eng 29(11):04017224

48. Wang C, Song Z, Gao Z, Yu G, Wang S (2019) Preparation and performance research of stacked piezoelectric energy-harvesting units for pavements. Energy Buildings 183:581-591

49. Jasim A, Wang H, Yesner G, Safari A, Maher A (2017) Optimized design of layered bridge transducer for piezoelectric energy harvesting from roadway. Energy 141:1133-1145

50. Cao Y, Sha A, Liu Z, Li J, Jiang W (2020) Energy output of piezoelectric transducers and pavements under simulated traffic load. J Cleaner Prod 279(123508). https://doi.org/10.1016/j.jclepro.2020.123508.

51. Du S, Petrie J, Shi X (2017) Use of snow fences to reduce the impacts of snowdrifts on highways: renewed perspective. Transp Res Rec 2613(1):45-51

52. Nabavi S, Zhang L (2016) Portable wind energy harvesters for low-power applications: a survey. Sensors 16(7):1101

53. Asanov I, Sharaborova E, Loktionov E (2019) Evaluation of technical and economic effect from setup of distributed photovoltaic generation on the right-of-way land of the North Caucasus railway. In: E3S Web of Conferences, vol 114. International Conference of Young Scientists "Energy Systems Research 2019", Irkutsk, p 05004

54. Qiao W, Sharma A, Hudgins JL, Jones EG, Rilett L (2011, July) Wind/solar hybrid generation-based roadway microgrids. In: 2011 IEEE power and energy society general meeting. IEEE, Detroit, pp 1-7

55. Datta U, Dessouky S, Papagiannakis AT (2017) Harvesting thermoelectric energy from asphalt pavements. Transp Res Rec 2628(1):12-22 
56. Han B, Zhang K, Burnham T, Kwon E, Yu X (2012) Integration and road tests of a self-sensing CNT concrete pavement system for traffic detection. Smart Mater Struct 22(1):015020

57. Liu X, Liu W, Wu S, Wang C (2014) Effect of carbon fillers on electrical and road properties of conductive asphalt materials. Constr Build Mater 68:301306

58. Xiang T, Huang K, Zhang H, Zhang Y, Zhang Y, Zhou Y (2020) Detection of moving load on pavement using piezoelectric sensors. Sensors 20(8):2366

59. Shi $X$, Huang J, Yang Z (2018) Chapter 18: pavement treatments for sustainable winter road maintenance. In: Shi X, Fu L (eds) Sustainable Winter Road Operations. Wiley-Blackwell, USA pp 402-422

60. Pan P, Wu S, Xiao F, Pang L, Xiao Y (2015) Conductive asphalt concrete: a review on structure design, performance, and practical applications. J Intell Mater Syst Struct 26(7):755-769

61. Zhang Y, Liu Z, Shi X (2020) A Review on Anti-lcing Asphalt Pavement with Salt-Storage Additive. ASCE J Transportation Eng, Part B: Pavements in press

62. Saleh NF, Zalghout AA, Sari Ad Din SA, Chehab GR, Saad GA (2020) Design, construction, and evaluation of energy-harvesting asphalt pavement systems. Road Mater Pavement Design 21(6):1647-1674

63. Johnsson J (2017) Winter road maintenance using renewable thermal energy (Doctoral dissertation, Chalmers Tekniska Hogskola (Sweden))

64. FHWA (2020). "ITS ePrimer", developed for the ITS professional capacity building program. [online]. https://www.pcb.its.dot.gov/eprimer/module13. aspx. Accessed on 1 Sept 2020.

65. Barbaresso JC, Johnson P (2014) Connected vehicle infrastructure deployment considerations: lessons learned from the safety pilot model deployment; report contract no. DTFH61-11-C-00040. HNTB corporation, for University of Michigan Transportation Research Institute, Ann Arbor, p 49

66. Iteris (2019). "Applications". Connected Vehicle Reference Implementation Architecture. [Online]. Available: https://local.iteris.com/cvria/html/ applications/applications.html. Accessed on 20 May 2019.

67. Chowdhury M, Rahman M, Rayamajhi A, Khan SM, Islam M, Khan Z, Martin J (2018) Lessons learned from the real-world deployment of a connected vehicle testbed. Transp Res Rec 2672(22):10-23

68. Wang S, Li Z (2019) Roadside sensing information enabled horizontal curve crash avoidance system based on connected and autonomous vehicle technology. Transp Res Rec 2673(5):49-60

69. Theriot M, Osman OA, Ishak S, Alecsandru C, Mousa SR, Bakhit PR (2017) Impact of Connected-Vehicle Market Penetration on the Effectiveness of Blind Spot Warning Applications: A Driving Simulation Study (no. 17-04930)

70. Howe G, Xu G, Hoover D, Elsasser D, Barickman F (2016) Commercial connected vehicle test procedure development and test results-blind spot warning/lane change warning (no. DOT HS 812 317)

71. Liu H, Wei H, Zuo T, Li Z, Yang YJ (2017) Fine-tuning ADAS algorithm parameters for optimizing traffic safety and mobility in connected vehicle environment. Transport Res Part C: Emerging Technol 76:132-149

72. He X, Zeng D (2017, November) Real-time pedestrian warning system on highway using deep learning methods. In: 2017 International Symposium on Intelligent Signal Processing and Communication Systems (ISPACS). IEEE, Xiamen, pp 701-706

73. Gungor OE, Al-Qadi IL (2020) All for one: centralized optimization of truck platoons to improve roadway infrastructure sustainability. Transport Res Part C: Emerg Technol 114:84-98

74. Ye, Z., Strong, C. K., Shi, X., Conger, S. M., \& Huft, D. L. (2009). Benefit-cost analysis of maintenance decision support system. Transportation research record, 2107(1), 95-103.

75. Rennie, C. J., \& Groeneweg, K. K. (2017). U.S. Patent No. 9,601,015. Washington, DC: U.S. Patent and Trademark Office.

76. Li H, Wolf JC, Mathew JK, Navali N, Zehr SD, Hardin BL, Bullock DM (2020) Leveraging connected vehicles to provide enhanced roadway condition information. J Transport Eng, Part A: Syst 146(8):04020073

77. Gopalakrishna D, Serulle NU, Kitchener F, Garrett K, Newton D (2016) Guidelines for deploying connected vehicle-enabled weather responsive traffic management strategies (no. FHWA-JPO-17-478). Federal Highway Administration, United States

78. Khazraeian S (2017) Methods for utilizing connected vehicle data in support of traffic bottleneck management. In: FIU Electronic Theses and Dissertations, vol 3496. Dissertation for Civil Engineering, Florida International University, Miami. https://digitalcommons.fiu.edu/etd/3496

79. Head, L. (2016, June). The multi modal intelligent traffic signal system (MMIT SS): a connected vehicle dynamic mobility application. In Mid Year Meeting,
Traffic Signal Systems Committee, Transportation Research Board, MMITSS. I95.06 (20). https://tetcoalition.org/wp-content/uploads/2016/03/Head. MMITSS.I-95.06.20.2016.pdf

80. Yao Z, Jiang Y, Zhao B, Luo X, Peng B (2020) A dynamic optimization method for adaptive signal control in a connected vehicle environment. J Intell Transp Syst 24(2):184-200

81. Huang L, Zhai C, Wang H, Zhang R, Qiu Z, Wu J (2020) Cooperative adaptive cruise control and exhaust emission evaluation under heterogeneous connected vehicle network environment in urban city. J Environ Manag 256:109975

82. Genders W, Razavi SN (2016) Impact of connected vehicle on work zone network safety through dynamic route guidance. J Comput Civ Eng 30(2): 04015020

83. Akin, M., He, Y., \& Shi, X. (2018). The Use of Connected Vehicle Technology to Facilitate Multimodal Winter Travel (Phase I) (No. Project ID: 2017 Project 09). Final report for the Center for Advanced Multimodal Mobility Solutions and Education, Charlotte, NC

84. Young RK, Welch BM, Siems-Anderson AR (2019) Generating Weather Alerts Including High Wind Blowover Hazards Using Pikalert ${ }^{\circledR}$ for the Wyoming Connected Vehicle Pilot Project (no. 19-02065)

85. Li H, Peters L, Banuelos C, Zaugg J, Sharma A, Bullock DM (2019a) Leveraging snow plow dashboards cams and connected vehicle speed data to improve winter operations performance measures

86. Li X, Medal H, Qu X (2019b) Connected infrastructure location design under additive service utilities. Transp Res B Methodol 120:99-124

87. Chang J (2017) An overview of USDOT connected vehicle roadside unit research activities (no. FHWA-JPO-17-433). Dept. of Transportation. ITS Joint Program Office, United States

88. NOCoE (2020) Implementation Guide: SPAT Challenge. National Operations Center of Excellence [Online]. Available: https://www.transportationops.org/ spatchallenge/resources/Implementation-Guide. Accessed on 20 May 2020

89. Najafi S, Flintsch GW, Khaleghian S (2016) Fuzzy logic inference-based pavement friction management and real-time slippery warning systems: a proof of concept study. Accid Anal Prev 90:41-49

90. Muller G (2012) Fuzzy architecture assessment for critical infrastructure resilience. Procedia Comput Sci 12:367-372

91. Sukuvaara T, Nurmi P (2012) Connected vehicle safety network and road weather forecasting-the WiSafeCar project. In: Proceedings of the 16 th international road weather conference, SIRWEC 2012, pp 23-25

92. Ma Y, Chowdhury M, Sadek A, Jeihani M (2012) Integrated traffic and communication performance evaluation of an intelligent vehicle infrastructure integration (VII) system for online travel-time prediction. IEEE Trans Intell Transp Syst 13(3):1369-1382

93. Balakrishna C (2012, September) Enabling technologies for smart city services and applications. In: 2012 sixth international conference on next generation mobile applications, services and technologies. IEEE, Paris, pp 223-227

\section{Publisher's Note}

Springer Nature remains neutral with regard to jurisdictional claims in published maps and institutional affiliations.

\section{Submit your manuscript to a SpringerOpen ${ }^{\circ}$ journal and benefit from:}

- Convenient online submission

- Rigorous peer review

- Open access: articles freely available online

- High visibility within the field

- Retaining the copyright to your article

Submit your next manuscript at $>$ springeropen.com 